\title{
A prickly situation: an attempted Caterpillar ingestion - case report
}

Amar K. Bhardwaj', Naif Fnais ${ }^{2,3}$ and Christopher J. Chin ${ }^{1,4,5^{*}}$

\begin{abstract}
Background: Foreign body ingestion is a common problem in pediatrics. Each foreign body can present its' own unique challenges during removal, and we present the management of an ingested Spotted Tussock Moth (Lophocampa maculata), more commonly known as a caterpillar.

Case presentation: An 18-month-old boy presented to the emergency department with difficulty handling secretions and odynophagia. It was reported he had placed a caterpillar in his mouth and then spat it out. On examination, hundreds of miniscule filaments (setae) were seen embedded in his lips and tongue. Our service was consulted out of concern for airway involvement. The patient was taken to the operating room where a direct laryngoscopy under general anesthesia with spontaneous ventilation was performed to confirm the setae were confined to the anterior tongue and lips. Once we were satisfied the airway was stable, the airway was secured, and we then began to remove the setae. The initial method used was to use Adson-Brown forceps to remove the setae, however this proved difficult and time-consuming given the volume of setae and how thin the setae were. Ultimately, a more effective technique was developed: a $4 \times 4$ AMD-RITMES ${ }^{\circledR}$ gauze was applied to the mucosa in order to dry up any secretions and then a piece of pink, waterproof BSN medical ${ }^{\oplus}$ tape was applied to the mucosa. After $3 \mathrm{~s}$ of contact it was removed. This technique was then repeated and was used to remove the vast majority of the setae.
\end{abstract}

Conclusion: To our knowledge, we have described the first technique to remove the caterpillar setae from the oral cavity mucosa in a fast, safe and efficient manner.

Keywords: Foreign body ingestion, Caterpillar, Otolaryngology, Case report

\section{Background}

Foreign body (FB) ingestion is a common problem in pediatrics and can present with upper airway obstruction. The presentation is variable depending on the $\mathrm{FB}$, and whether the FB is aspirated on ingestion, but it can present with drooling, choking, dysphagia, odynophagia and chest pain. We present an unusual case of a (fortunately) failed attempt to ingest a caterpillar in an 18month-old boy. The case highlights the difficulty in

\footnotetext{
* Correspondence: Christopher.Chin@dal.ca

'Dalhousie Medicine New Brunswick, Saint John, New Brunswick, Canada

${ }^{4}$ Department of Surgery, Division of Otolaryngology - Head and Neck Surgery, Saint John, New Brunswick, Canada

Full list of author information is available at the end of the article
}

treating each unique FB, as the caterpillar 'spines' presented a challenge for removal.

\section{Case presentation}

An 18-month-old boy presented to the emergency department with difficulty handling secretions and odynophagia. It was reported by his parents he had placed a caterpillar in his mouth and then spat it out. The caterpillar was identified as a Lophocampa maculata (Spotted tussock moth) by visual comparison to other referenced images by the parents (Fig. 1). On examination, hundreds of miniscule filaments (setae) were seen embedded in his lips and tongue. The patient was assessed in the Emergency department and,

(c) The Author(s). 2020 Open Access This article is licensed under a Creative Commons Attribution 4.0 International License, which permits use, sharing, adaptation, distribution and reproduction in any medium or format, as long as you give appropriate credit to the original author(s) and the source, provide a link to the Creative Commons licence, and indicate if changes were made. The images or other third party material in this article are included in the article's Creative Commons licence, unless indicated otherwise in a credit line to the material. If material is not included in the article's Creative Commons licence and your intended use is not permitted by statutory regulation or exceeds the permitted use, you will need to obtain permission directly from the copyright holder. To view a copy of this licence, visit http://creativecommons.org/licenses/by/4.0/ The Creative Commons Public Domain Dedication waiver (http://creativecommons.org/publicdomain/zero/1.0/) applies to the data made available in this article, unless otherwise stated in a credit line to the data. 


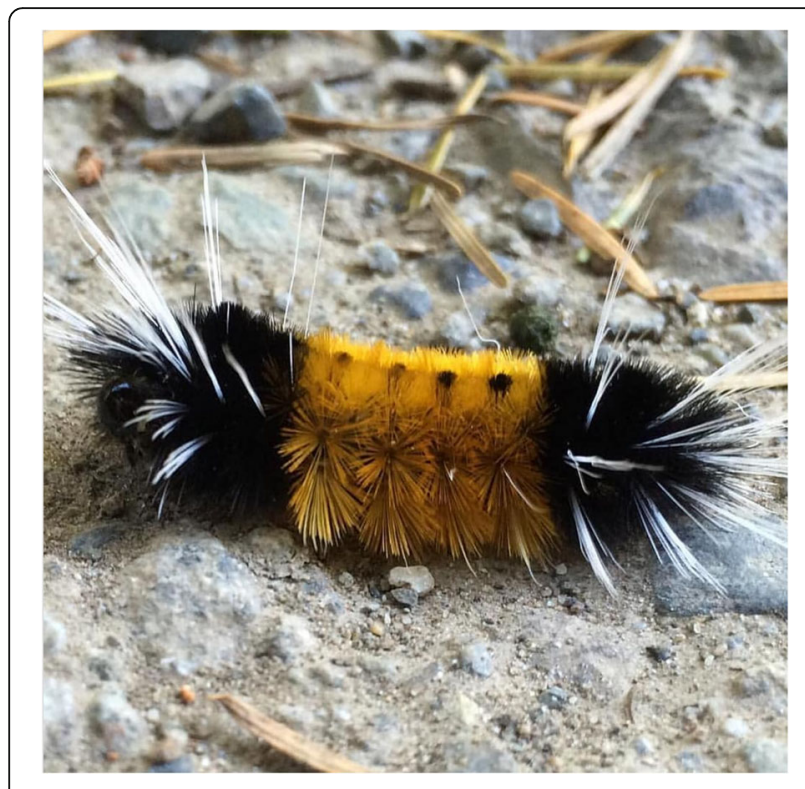

Fig. 1 Image of the Spotted tussock moth Caterpillar (Lophocampa maculata) [1]

because of the difficulty handling secretions, Otolaryngology- Head and Neck Surgery was consulted.

Upon initial assessment, the patient was drooling significantly but there was no stridor or dysphonia heard. The anterior tongue, buccal mucosa and lips were coated in setae (Fig. 2). It was decided the patient should be examined in the operating room to rule our laryngeal/hypopharyngeal involvement, and to remove the setae. The patient was taken to the operating room. After induction of general anaesthesia with spontaneous ventilation, direct laryngoscopy was performed to assess the upper airway and oropharynx. There was no evidence of setae in the oropharynx or larynx and it was confirmed the setae were confined to the anterior tongue and lips, with no evidence of upper airway edema. Once we were satisfied the airway was stable, the airway was handed back to the anesthesia service and secured via endotracheal intubation.

At this point, we began the removal of the setae from the patient's lip, tongue and buccal mucosa. The initial method used was to use Adson-Brown forceps to remove the setae, however this proved difficult and time-consuming given the large volume and how fine the setae were. Ultimately, a more effective technique was developed: a $4 \times 4$ AMD-RITMES ${ }^{\circ}$ gauze was applied to the mucosa in order to dry up any secretions and then a piece of pink, adhesive waterproof BSN medical $^{\circ}$ tape was applied to the mucosa. After approximately $3 \mathrm{~s}$ of contact, the tape was removed. This technique was then repeated and was used to remove the majority of the setae. It should be noted that not all small filaments were removed, with a few left embedded in the mucosa and within the tongue papillae, as these were quite difficult to extract. The patient was then reversed from general anesthesia, extubated and transferred to the post-anesthesia care unit in stable condition. The child was admitted overnight to observe for any potential complications such as delayed systemic toxicity. The patient was discharged the following day with no further issues.

\section{Discussion}

Ingested foreign bodies are a common clinical problem primarily seen in children; $56.6 \%$ of patients are between 1 and 3 years of age [2]. The most common site for a foreign body to get stuck is the hypopharynx, particularly at the cricopharyngeal sphincter [2].

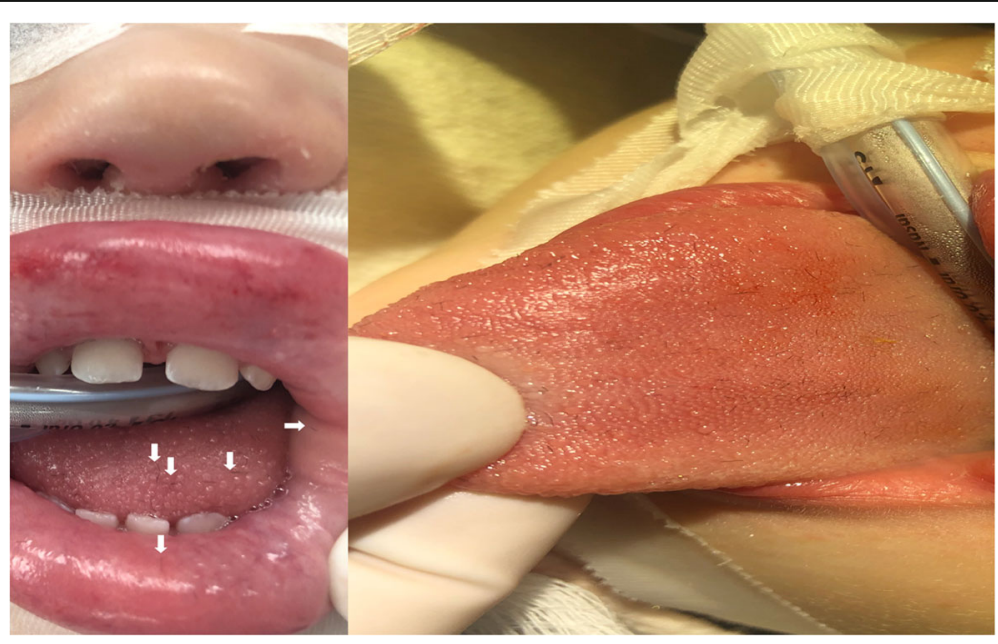

Fig. 2 Miniscule filaments (Setae) embedded (arrowheads) in the tongue and lips 
The foreign body presented in this case is a wellknown insect: The Caterpillar, with over 150,000 different species described [3]. In Canada, namely, New Brunswick, there are 1593 described variants [3], some of which are poisonous. On appearance, caterpillars have spines and hair like structures on their exterior. In some species, it serves as a defence mechanism and the hairs (setae) and spikes can sting their foe, leading to adverse reactions in the recipient, mainly cutaneous reactions, include dermatitis and localized reactions.

Lepidopterism (the general term which refers to the toxic effects of caterpillars) leads to clinical signs that vary from urticarial wheels to conjunctivitis, pharyngitis, malaise, and rarely, anaphylactic reactions [4]. Therefore, minimizing exposure to the setae in the oral cavity and oropharynx is important in these cases. To our knowledge, this is the first reported case of oral cavity exposure to the Lophocampa maculata species, and we have reported on a method to remove the setae atraumatically in this location. While tape has been used anecdotally to remove the setae from the skin, in the oral cavity the saliva makes it considerably less effective, unless the mucosa is dried first with gauze.

There are toxic strains of caterpillars to be aware of, namely the Hickory tussock (Lophocampa caryae) and Io moth caterpillar (Automeris io). The Hickory tussock moth caterpillar has a characteristic row of black tufts that are responsible for the caterpillar's toxicity along with white hairs along its side. Envenomization occurs when the recipient presses their hairs that release toxins such as proteolytic enzymes, histamine and other pro inflammatory substances [5]. The Io moth caterpillar (Automeris io) has a pale yellow to green color with red true legs and prolegs. These caterpillars release their venom from the tips breaking off when they penetrate skin leading to subsequent irritation. In our case, there was a risk of venom release with subsequent airway edema, and potentially, critical airway obstruction. Therefore, it was imperative to quickly evaluate and secure the airway. Balit et al. have described in a report pertaining to the cutaneous manifestations of the white-stemmed gum moth that attempted removal of all setae is near impossible, non-essential and time consuming [6]. Another case report describes an anaphylactic reaction to the Lophocampa maculata species with cutaneous manifestations [7]. The patient's anaphylactic reaction manifested with an acute development of diffuse urticaria along with progressive dyspnea [7]. To our knowledge, this is the first reported case of oral cavity exposure to the Lophocampa maculata species, and we have reported on a method to remove the setae atraumatically in this location. While tape has been used anecdotally to remove the setae from the skin, in the oral cavity the saliva makes it considerably less effective, unless the mucosa is dried first with gauze.

\section{Conclusion}

Following potential ingestion of a caterpillar, the setae embedded in the oral mucosa should be removed in order to minimize potential complications. To our knowledge, we have described a novel technique to remove the caterpillar setae from the oral cavity mucosa in a fast, safe and efficient manner. The use of adhesive waterproof tape, preceded by application of gauze to dry up the mucosa to allow good contact, allowed for timely removal of caterpillar filaments.

\section{Authors' contributions \\ All authors wrote, reviewed, and edited the manuscript. CJC and NF proposed the idea for this report. The authors read and approved the final manuscript before submission. CJC and NF were involved in the intervention and management of the patient.}

\section{Funding}

The authors declare that there is no funding to disclose.

Availability of data and materials

Not applicable.

\section{Ethics approval and consent to participate}

Ethics approval was obtained from the Institutional Research Ethics Board of the Saint John Regional Hospital (approval waived). Consent was obtained from the patient's mother in writing.

Consent for publication

Consent was obtained from the patient's mother for this case report.

\section{Competing interests}

The authors declare they have no competing interests.

\section{Author details}

${ }^{1}$ Dalhousie Medicine New Brunswick, Saint John, New Brunswick, Canada. ${ }^{2}$ Department of Otolaryngology- Head and Neck Surgery, McGill University, Montreal, Quebec, Canada. ${ }^{3}$ Department of Otolaryngology- Head and Neck Surgery, King Saud University, Riyadh, Saudi Arabia. ${ }^{4}$ Department of Surgery, Division of Otolaryngology - Head and Neck Surgery, Saint John, New Brunswick, Canada. ${ }^{5}$ Department of Surgery, Division of Otolaryngology Head and Neck Surgery, Dalhousie University, Halifax, Nova Scotia, Canada.

Received: 26 May 2020 Accepted: 21 September 2020

Published online: 29 September 2020

\section{References}

1. The BiodiversO'Fists. A spotted tussock moth Caterpillar, Lophocampa maculata. Instagram. 2018; Available from: https://www.instagram.com/p/ BnSa_jVFzdz/.

2. Awad A, Eltaher M. ENT foreign bodies: an experience. Int Arch Otorhinolaryngol. 2017;22(02):146-51.

3. Pohl GR, Landry J-F, Schmidt BC, Dewaard JR. Lepidoptera of Canada. ZooKeys. 2019;819:463-505.

4. Müller CSL, Tilgen W, Pföhler C. Caterpillar dermatitis revisited: lepidopterism after contact with oak processionary caterpillar. BMJ Case Rep. 2011;2011: bcr0320113967.

5. Villas-Boas IM, Bonfá G, Tambourgi DV. Venomous caterpillars: from inoculation apparatus to venom composition and envenomation. Toxicon. 2018;153:39-52. 
6. Balit CR, Geary MJ, Russell RC, Isbister GK. Clinical effects of exposure to the white-stemmed gum moth (Chelepteryx collesi). Emerg Med Australas. 2004;16:74-81.

7. Dugar B, Sterbank J, Tcheurekdjian H, Hostoffer R. Beware of the caterpillar: anaphylaxis to the spotted tussock moth caterpillar, Lophocampa maculata. Allergy Rhinol. 2014;5(2):113-5.

\section{Publisher's Note}

Springer Nature remains neutral with regard to jurisdictional claims in published maps and institutional affiliations.

Ready to submit your research? Choose BMC and benefit from:

- fast, convenient online submission

- thorough peer review by experienced researchers in your field

- rapid publication on acceptance

- support for research data, including large and complex data types

- gold Open Access which fosters wider collaboration and increased citations

- maximum visibility for your research: over $100 \mathrm{M}$ website views per year

At BMC, research is always in progress.

Learn more biomedcentral.com/submissions 